\title{
Overview of BIM Implementation in Singapore and Japan
}

\author{
Takashi Kaneta, Shuzo Furusaka, Atsushi Tamura and Nisi Deng \\ Department of Architecture and Architectural Engineering, Kyoto University, Kyoto 615-8540, Japan
}

\begin{abstract}
This paper aims to overview BIM (building information modeling) implementation in Singapore and to clarify the problems concerned with BIM in Singapore and Japan. The Singapore BIM Roadmap and related policies developed by BCA (Building and Construction Authority) are introduced at first along with the background and environment in Singapore. Despite of the assessment from Japan, BIM implementation in Singapore is not always perfect and well-equipped according to the authors' interviews to Japanese general contractors operating in Singapore. Japanese general contractors have ability to produce and coordinate design drawings and shop drawings by hiring in-house architects and engineers. The client and the architects can reduce project risk concerning design and drawings by transferring it to the general contractor. The authors discuss the problems on project management to show the strategy to develop the new version of BIM, hoping to share the value with all of the stakeholders of the project.
\end{abstract}

Key words: Building information modeling, general contractor, architect, drawing, project management.

\section{Introduction}

There are a lot of risk and uncertainty that were not predicted on the contract, but they appear suddenly along with the progress of the building project. In order to avoid such risk or uncertainty, the owner contracts out the majority of projects to the general contractor and outside parties. When BIM (building information modeling) is introduced to the project, it is assumed to reduce risk and uncertainty concerning with design drawings and documents because BIM is based on only one set of fixed objects of the building.

Comparing with Japan, Singapore is a developed country from the view of BIM environment. For example, BIM e-submission for design document is completely implemented by Singaporean regulations.

This research aims to clarify the reality of effect of BIM to reduce risk and uncertainty of the project, especially in this paper, the authors describe the overview of BIM implementation and discuss the problems concerned with BIM in Japan and Singapore.

The authors made interviews to staffs of Building Construction Authority of Singapore, architects and

Corresponding author: Takashi Kaneta, associate professor, research fields: construction management. E-mail: kaneta@archi.kyoto-u.ac.jp. general contractors in Singapore.

Then the authors found the facts as follows:

- Even after BIM e-submission was obliged, design documents are not coordinated enough among architectural, structural, mechanical, electrical and plumbing drawings;

- The risk and uncertainty on design drawings have not reduced as for general contractors;

- General contractors have obligation to coordinate the design for shop drawings in construction contract, which enlarges the load to use BIM.

On the other hand, BIM implementation in Japan is not always encouraged with top-down consensus in architects firm and general contractors as the client of the project is not aware of the value and incentive to introduce BIM use into the contracts of the project. Japanese general contractors have ability to produce and coordinate architectural drawings and shop drawings by hiring in-house architects and engineers. The client and the architects can reduce project risk concerning design and drawings by transferring it to the general contractor. So they are not sensitive to the schedule to decision making in the project process and they need not introduce BIM. The authors discuss the problems on project management to show the strategy to develop the new version of BIM, hoping to share the 
value with all of the stakeholders of the project.

\section{Methods}

A survey was conducted to grasp the background and facts concerning with implementation of BIM in Singapore as shown in Tables 1-3.

\section{BIM Implementation in Singapore}

\subsection{Background}

There are two reasons why BIM should be implemented in Singapore.

One is to reduce the number of foreign workers. About $1 / 3$ of the residents in Singapore are foreigners. Foreign workers have played important roles as blue-collar labors in industries since foundation of Singapore. They are trained and certified as skilled/multi skilled workers in their home countries, e.g., India, Bangladesh, Myanmar, China, but their skills do not still meet the requirement of general contractors. Singaporean Government has a policy to reduce foreign workers in construction industry by implementing BIM to design and construction process.

Another is to improve the productivity. Productivity in Japanese construction industry was a hot topic in 1980s concerning schedule recovery from the delay caused by troubles with stakeholders surrounding the construction site. There is no room to improve productivity in Japanese construction industry, but now skilled workers are going out of the industry, which brings the difficulty to keep the productivity and quality assurance in Japan. This phenomenon may be called as " 2 nd Stage to Improve the Productivity".

\subsection{Singapore BIM Roadmap}

In Singapore, the BCA (Building and Construction Authority) implemented the BIM Roadmap in 2010 with the aim that $80 \%$ of the construction industry will use BIM by 2015 [1]. This is part of the government's plan to improve the productivity by up to $25 \%$ over the next decade. To allow the public sector to take the lead, BCA collaborated with GPEs (government procurement entities) to request the use of BIM for their projects from 2012. These are remarkable policy to lead the industry.

\subsection{Singapore BIM Guide}

BCA published The Singapore BIM Guide and The BIM Particular Conditions in 2012 [2]. BIM Guide is part of the industry's efforts to demystify BIM and to give clarity on the requirement of BIM usage at different stages of a project. The use of BIM can be incorporated into the project as part of the scope of

Table 1 Outline of survey.

\begin{tabular}{ll}
\hline Method & Interview \\
\hline \multirow{2}{*}{ Object } & BCA (Building and Construction Authority) \\
\cline { 2 - 2 } & NUS (National University of Singapore) \\
\hline Date & March 8-12, 2016 \\
\hline
\end{tabular}

Table 2 Topics of interview (general contractors).

\begin{tabular}{ll}
\hline 1 & Are there any difficulties or troubles with BIM e-submission? \\
\hline 2 & Do you use the same BIM software both in Japan and Singapore? \\
\hline 3 & $\begin{array}{l}\text { What is the good and bad point with BIM? } \\
\text { Is it the same in Japan? }\end{array}$ \\
\hline
\end{tabular}

Table 3 Topics of interview (BCA and NUS).

\begin{tabular}{ll}
\hline 1 & Does it meet the requirements as defined in Guideline for Architectural Discipline? \\
\hline 3 & If it is successful, why? \\
\hline
\end{tabular}


Table 4 BIM e-submission template.

\begin{tabular}{lllll}
\hline & Revit & ARCHICAD & AECOsim & Tekla \\
\hline Architectural BIM e-submission & $\mathrm{x}$ & $\mathrm{x}$ & $\mathrm{x}$ & \\
\hline Structural BIM e-submission & $\mathrm{x}$ & $\mathrm{x}$ & $\mathrm{x}$ \\
\hline MEP (mechanical, electrical and plumbing) BIM e-submission & $\mathrm{x}$ & $\mathrm{x}$ & \\
\hline
\end{tabular}

services under the principal agreement with the help of BIM particular conditions.

BIM Essential Guide For BIM Execution Plan [3] includes a BIM execution plan template which is necessary for each construction project.

It is mandatory for new building projects over $5,000 \mathrm{~m}^{2}$ to use BIM e-submission via Corenet on the web [4]. Templates for BIM e-submission are provided as shown in Table 4 to help the design firms to prepare for the regulatory submission.

\subsection{Singapore BIM Fund}

Singapore BIM fund, launched in 2012 and updated in 2013 and 2015, aims to help design firms build up BIM collaboration capability by defraying part of the cost incurred in training, consultancy, software or hardware [5]. General contractors from Japan also applied for this fund, and they are grateful for this financial support by Singaporean Government.

\section{BIM Adaptation to Projects in Singapore}

\subsection{BIM and Stakeholders}

Singapore Government has a policy to lead the implementation of BIM, whereas clients in private sector are evaluating the value and cost of BIM. It is obliged for architects and consulting engineers to use BIM for design. But the quality and density of the design drawings as output of BIM are not always enough, moreover, the drawings are not coordinated one another in many projects. General contractors accept BIM from product manufacturers and give output of BIM to subcontractors.

In Singapore, there are typical new professionals called as BIM manager and BIM coordinator, who are not known to Japanese construction industry. They are responsible for the definition, management and completion of the BIM execution plan.

\subsection{BIM e-Submission}

Despite of the assessment from Japan, BIM e-submission in Singapore is not always perfect and well-equipped according to the authors' interviews to Japanese general contractors operating in Singapore.

Ideally, BIM should be only one model coordinated by lead architect. After regulatory submission, BIM should be sent to general contractor for construction planning as shown in Fig. 1. This will improve productivity because they need not input or rewrite design drawings many times.

Even after BIM e-submission was obliged, design documents are not coordinated enough among architecture, structure, mechanical, electrical and plumbing engineering as shown in Fig. 2.

To avoid this confusion, design drawings should be coordinated by a professional engineer who will be BIM manager as shown in Fig. 3. In Singapore, clients often contract consulting engineers as professional of BIM manager. In this case, BIM manager is the third party to integrate the design information other than architects or general contractors. The role of BIM manager in project delivery is still case by case basis.

\section{Barriers of BIM Implementation in Singapore}

\subsection{Difficulties of Projects in Singapore}

Comparing with Japan, Singapore is a developed country from the view of BIM environment. BIM e-submission for design document is completely implemented by Singaporean regulations. When BIM is adopted to the building project, it is assumed to reduce risk and uncertainty concerning with design drawings and documents, because BIM is based on only 


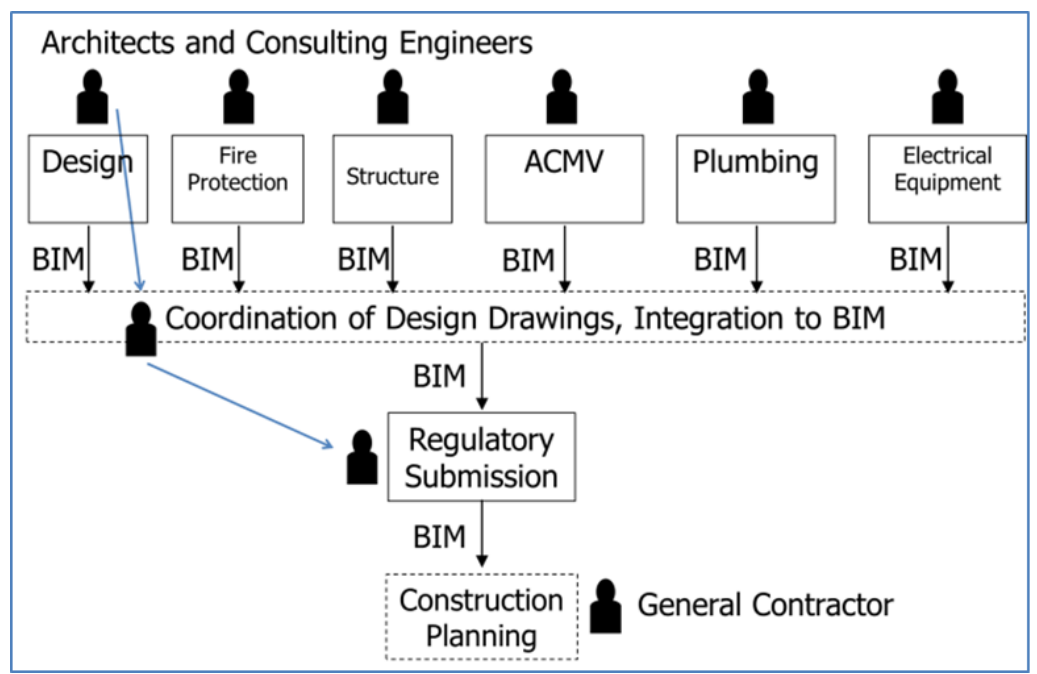

Fig. 1 BIM e-submission in ideal model.

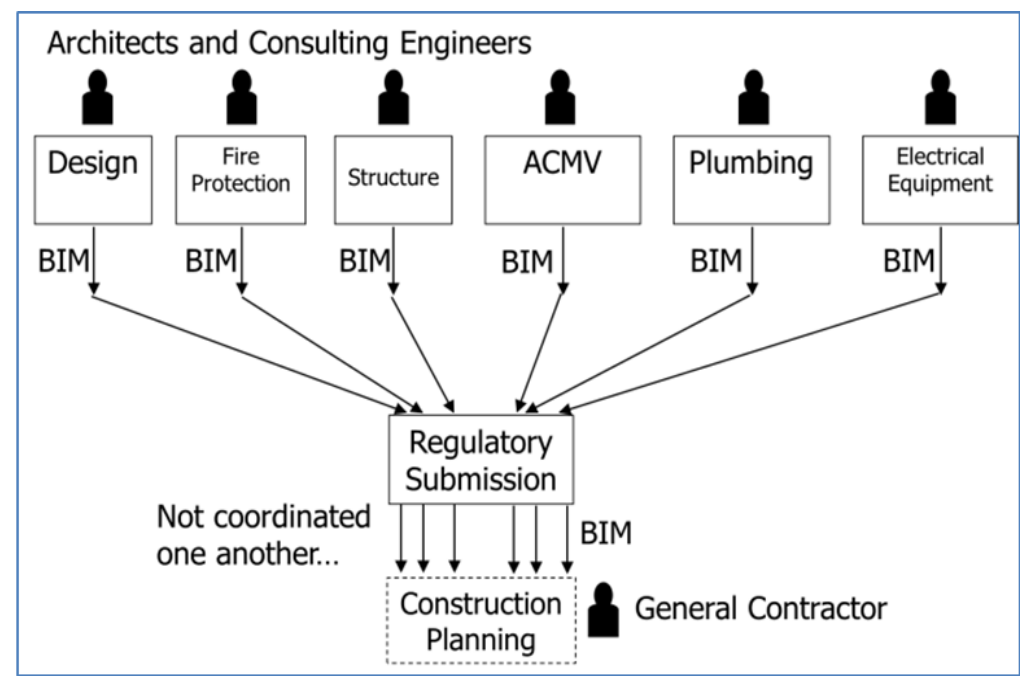

Fig. 2 BIM e-submission in "as-is" model.

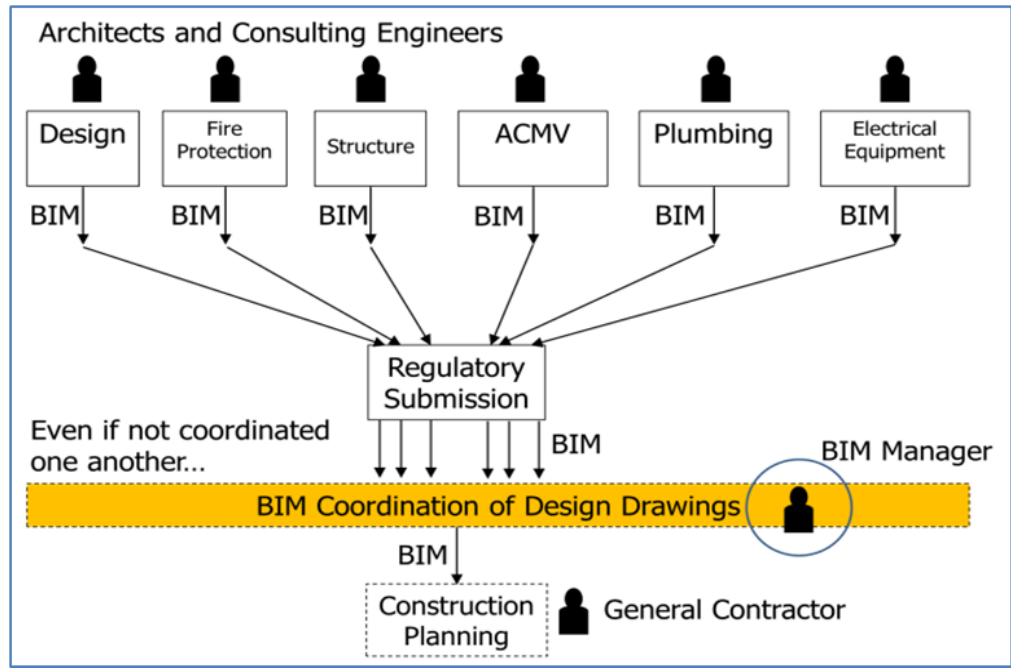

Fig. 3 BIM e-Submission in "to-be" model. 
one set of fixed objects of the building. However, according to the general contractors operating in Singapore, design drawings are not coordinated enough by design firms whether BIM is adopted or not. General contractors have obligation to coordinate the design for shop drawings in construction contract, which enlarges the load to use BIM.

\subsection{BIM Operators in Singapore}

BIM operators are coming from foreign countries such as the Philippines. They are generally excellent in operating software and information system. But as the training for spatial perception in their home countries may not be enough, some of the operators often misunderstand the solid or structure of the building.

To prevent the misunderstanding, some of general contractors from Japan assign BIM coordinator to encourage the modeling and to cover the design drawings and shop drawings in Singapore.

\subsection{Rely on 2D Drawings}

Even after BIM is adopted to the construction project, general contractors from Japan uses a lot of 2D drawings for decision making by site managers. Meetings with subcontractors are based on 3D BIM, however, the workers use $2 \mathrm{D}$ drawings printed on paper. The style and format of shop drawings do not sometimes fit to the output from BIM. In such cases, general contractors should replace BIM from the one accepted from the architects and consultant engineers.

\section{Differences between Japan and Singapore}

\subsection{Barriers of BIM Implementation in Japan}

BIM implementation in Japan is developing but not strategically uniformed, though MLIT (Ministry of Land, Infrastructure, Transport and Tourism) published BIM Guideline in 2014 after MLIT selected three pilot projects from public sector in 2010.

As shown in Fig. 4, BIM adopted in Japanese construction industry are not compatible one another through supply chain, because construction market in Japan is so huge. The top 5 super general contractors in Japan have about JPY1.4-1.8 trillion annual gross revenue, which declines the incentive for contractors to develop BIM compatible to other contractor's supply chain.

Generally speaking, Japanese firms are not eager to implement BIM as corporate level, because clients in Japan do not recognize the value created by BIM. There are no articles that encourage BIM implementation in construction contracts unless specially defined. So nobody covers the cost to set up BIM along with the contingency of the project is shrinking. BIM is still on the way to help stakeholders to reduce risk and uncertainty.

\subsection{BIM in Construction Industry of Japan and} Singapore

In Singapore, there are only a few kinds of BIM software that are certified for BIM e-submission template. They are de facto standard of BIM and they are compatible through supply chain consisted of product manufacturers, architects, consulting engineers, general contractors and subcontractors.

The construction market in Singapore is about JPY2.2 trillion in 2015 [6], which is small comparing with Japanese market [7]. It is reasonable to generalize BIM in Singapore above whole country.

\subsection{Design Works by Japanese General Contractors}

It is special culture uncommon to other countries that Japanese general contractors have ability to produce and coordinate design drawings and shop drawings by hiring in-house architects and engineers. With such general contractors, the client and the architects can reduce project risk concerning design and drawings by transferring the risk to the general contractors. So the clients and the architects in Japan are not sensitive to the schedule of decision making in the project process. In other words, they need not introduce BIM because 


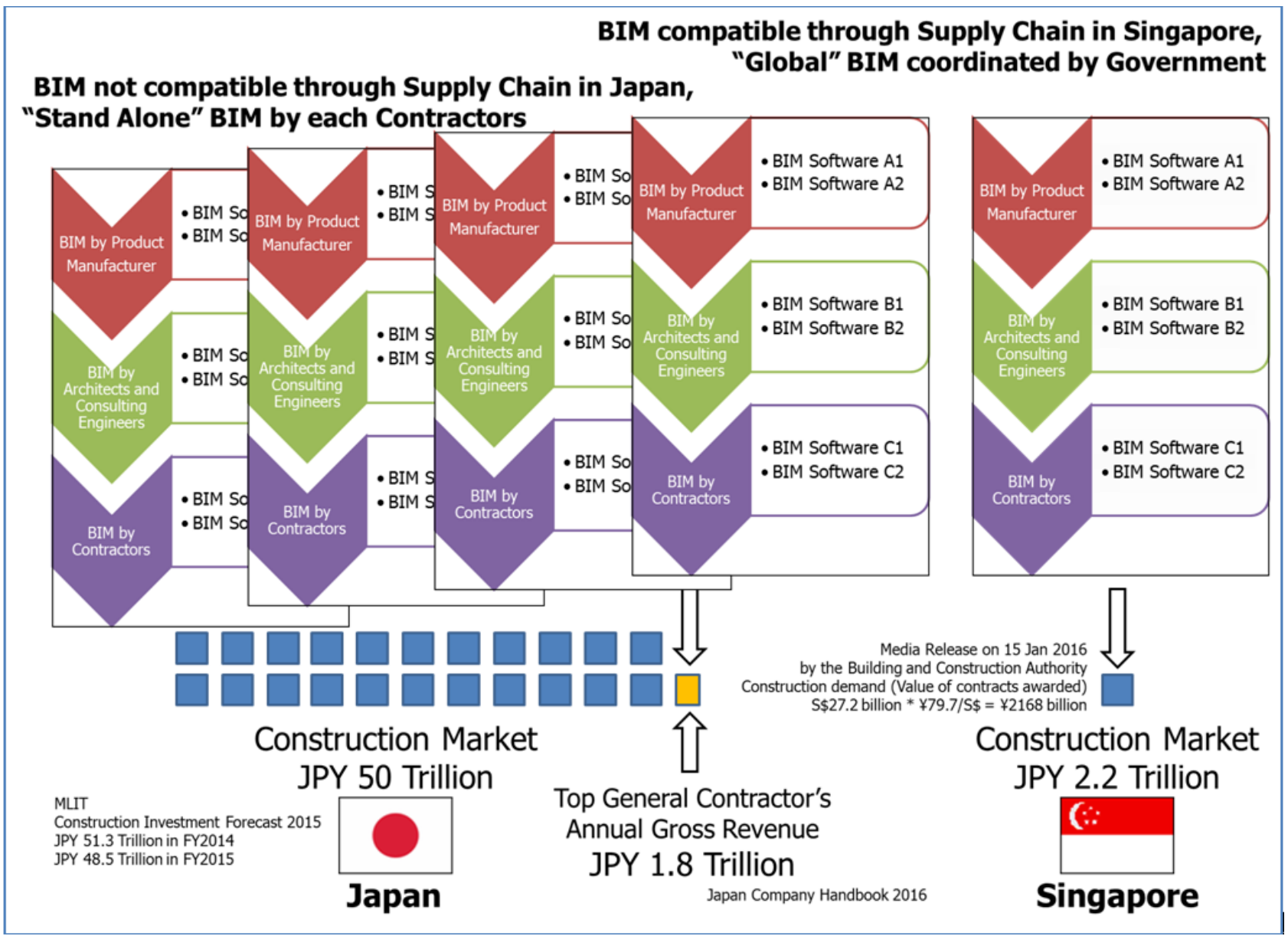

Fig. 4 BIM in construction industry of Japan and Singapore.

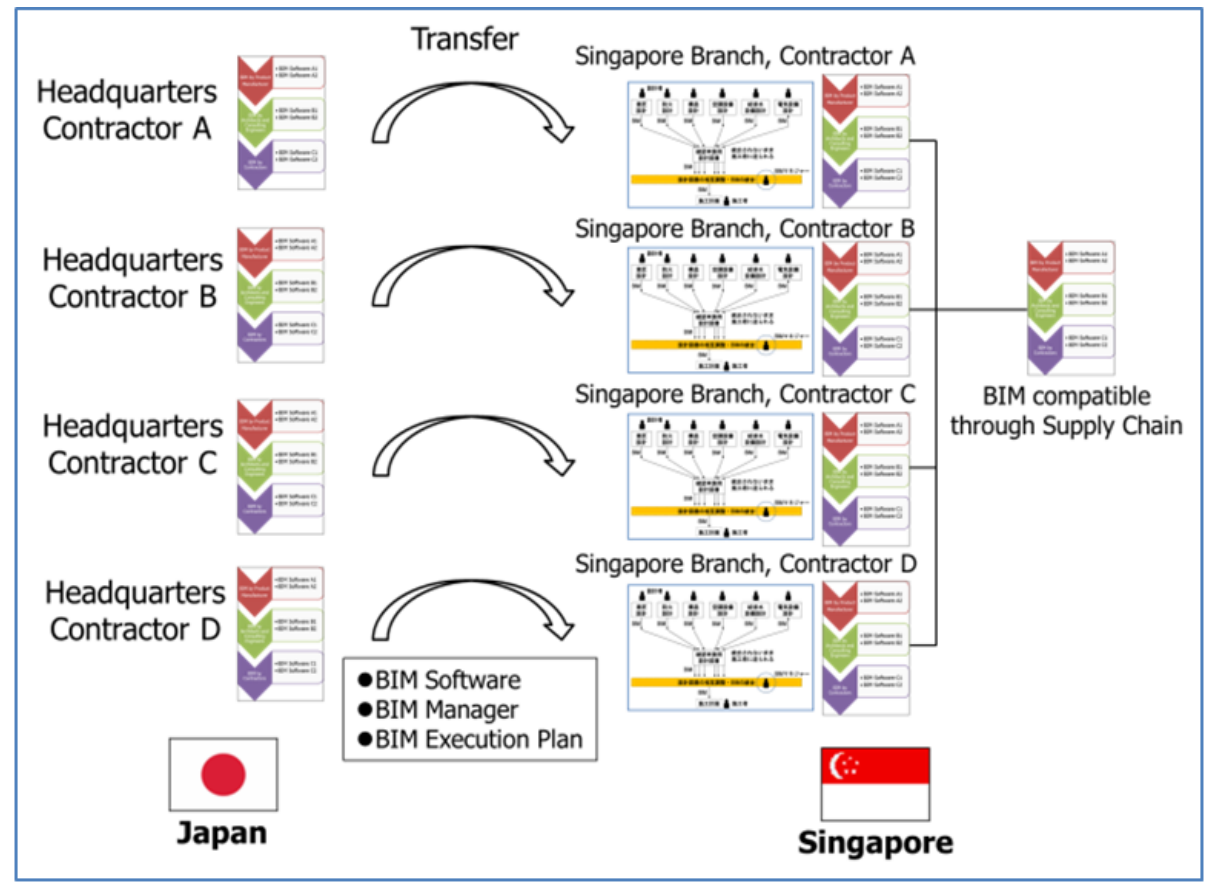

Fig. 5 Scheme of further analysis. 
front loading and integrated project delivery caused by BIM will make their loads larger in former stage of the projects.

\subsection{Research and Development of BIM in Japan}

The authors also reviewed past research such as product modeling, integrated information system for design and construction, and other original systems. The concept applied to BIM was already developed in 1990s. At that time, the trial to define common coding for all the general contractors was promoted by Japanese Government under the policy to enhance CALS/EC (continuous acquisition and life-cycle support/electronic commerce), which ended without success because of the competition with the de facto standard software.

As for the general contractors, full turn-key contract is attractive and suitable for BIM implementation to reduce the tasks to find and to check the conflicts in design drawings.

The design firms obtain the advantage to analyze big data and complicated geographical information by adopting BIM as well as an excellent tool for 3D presentation in design phase.

The major clients in Japan are interested in adopting BIM in facility management phase, using as-built BIM for procurement of reformation.

\section{Conclusions}

This paper described BIM implementation and indicated the barriers concerned with BIM in Japan and Singapore. BIM implementation in Singapore is led by BCA and Singaporean Government. It is a kind of regulation to make stakeholders together with BIM.

BIM implementation in Japan is not always encouraged with the board members in architect firm and general contractors as the client of the project is not aware of the value and incentive to express BIM use into the contracts of the project.

The authors discuss the problems on project management to show the strategy to develop the strategy of BIM implementation. Japanese general contractors have ability to produce and coordinate design drawings and shop drawings with in-house architects and engineers. So the client and the architects can reduce project risk concerning design and drawings only if they transfer it to the general contractor. They are not always responsible for the schedule of decision making in the project process and they need not introduce BIM.

So it can be concluded that BIM is still on the way to help stakeholders to reduce risk and uncertainty. But the authors prospect that there is also space for innovation by excellent general contractors, and the authors will propose a strategy for new business to manage the project utilizing BIM.

General contractors from Japan are operating BIM in Singapore compatible with open system of supply chain. This style is different from the one in Japan even they belong to the same company as shown in Fig. 5. Next step it should be analyzed in detail.

\section{Acknowledgments}

All the people and institutions that contributed to the survey are gratefully acknowledged. This research is supported by the Japan Society for the Promotion of Science (JSPS) Grants-in-Aid for Scientific Research, Challenging Exploratory Research 26630271.

\section{References}

[1] BCA. 2011. Singapore BIM Roadmap. Accessed June 15, 2016. https://www.bca.gov.sg/newsroom/others/pr0211 2011_BIB.pdf.

[2] BCA. 2013. Singapore BIM Guide Version2. Accessed June 15, 2016. https://www.corenet.gov.sg/media/ 586132/Singapore-BIMGuide_V2.pdf.

[3] BCA. 2013. BIM Essential GuideFor BIM Execution Plan. Accessed June 15, 2016. https://www.corenet.gov.sg/ media/586149/Essential-Guide-BEP.pdf.

[4] Singapore Government. 2016. BIM e-Submission. Accessed June 15, 2016. https://www.corenet.gov.sg/ general/ building-information-modeling-(bim)-e-submission.aspx.

[5] BCA. 2015. Singapore BIM Fund V2. Accessed June 15, 2016. https://www.bca.gov.sg/BIM/bimfund.html.

[6] BCA. 2016. Media Release. Accessed June 15, 2016. 


\section{Overview of BIM Implementation in Singapore and Japan}

https://www.bca.gov.sg/Newsroom/others/BCA_Media Release_Prospects_150116.pdf.

[7] Ministry of Land, Infrastructure, Transport and Tourism.
2015. Construction Investment Forecast 2015. Accessed June 15, 2016. http://www.mlit.go.jp/report/press/joho 04_hh_000561.html 